\title{
Clomiphene treatment may be effective in refractory episodic and chronic cluster headache
}

\author{
Tratamento de 15 casos episódicos e crônicos de cefaleia em salvas de difícil controle \\ com clomifeno
}

Maria Eduarda Nobre, Mario Fernando Prieto Peres², Pedro Ferreira Moreira Filho', Antonio José Leal ${ }^{3}$

\begin{abstract}
Objective: To describe the evolution of 15 patients who were treated for difficult-to-control episodic and chronic cluster headaches with clomiphene. Methods: Clomiphene treatment was used for seven chronic and eight episodic cluster headache patients. The chronic patients were refractory to the medication being used, and the episodic patients, in addition to being resistant to conventional medication, had longer cluster headache periods, exceeding the average time of previous cluster cycles. Our main analysis was of the time to pain-free, complete remission, and the length of pain-free time and complete remission. Results: Clomiphene was used for 45-180 days. The average time to being pain-free was 15 days and cluster remission was up to 60 days. The average time between being pain-free until cluster remission was 26 days. Conclusions: Clomiphene treatment was significantly efficient. It interrupted chronicity in all patients, suggesting the capability of changing the pattern of attacks. It proved to be safe and well tolerated.

Keywords: headache; therapeutics; testosterone; clomiphene; hypothalamus
\end{abstract}

\section{RESUMO}

Objetivo: Descrever a evolução de 15 casos de cefaleia em salvas de difícil controle, episódicos e crônicos, tratados com clomifeno. Métodos: Foram tratados 7 casos crônicos e 8 episódicos. Os crônicos, refratários aos medicamentos preventivos em uso e os episódicos, além de refratários, apresentaram salva mais longa que as anteriores. Foram analisados o tempo para a ausência das crises, fim da salva e o tempo entre os dois parâmetros. Resultados: 0 clomifeno foi usado por 45 a 180 dias. A média de tempo para a remissão das crises foi de 15 dias e da salva foi de 60 dias. A média entre o fim das crises e da salva foi de 26 dias. Conclusão: 0 clomifeno foi eficaz em ambos os padrões. Foi capaz de interromper a cronicidade em todos os casos, o que sugere uma ação neuromodulatória capaz de mudar o padrão das crises. Mostrou-se seguro e bem tolerado.

Palavras-chave: cefaleia; terapêutica; testosterona; clomifeno; hipotálamo

Patients who were treated for difficult-to-control episodic and chronic cluster headaches and results are described. Hypothalamic modulation by means of hormone treatment seems to be the new solution for preventive treatment.

Cluster headache is certainly the most painful and incapacitating of primary headaches, particularly for patients who suffer from long bouts or for those who present with the chronic form. Cluster headaches are characterized by a periorbital unilateral pain associated with ipsilateral autonomic signs (ptosis, miosis, conjunctival hyperemia, tearing, rhinorrhea, nasal congestion). Its episodic form is characterized by weeks or months (cluster periods) of pain, separated by painfree intervals of months or years ${ }^{1}$. Chronic cluster headaches affect nearly $10 \%$ of patients and episodes persist for at least one year with no remission or with remissions that last for at least one month. These patients usually need one or two preventive drugs such as corticosteroids, verapamil, and lithium carbonate, among others. The need for high doses is common, often making tolerability difficult. In addition, about $1 \%$ of patients become refractory to treatment ${ }^{1}$.

The hallmark of the cluster headache is its circadian and seasonal rhythmicity. Several studies have shown a hypothalamic involvement, initially suggested because of hormonal variation detected in patients and treatment results with lithium. The significant drop in plasma testosterone levels in cluster headache patients was the first evidence of hypothalamic involvement ${ }^{2}$. Romiti et al. ${ }^{3}$ showed a reduction in plasma testosterone only during bouts in episodic cluster headaches.

\footnotetext{
'Universidade Federal Fluminense, Departamento de Neurologia, Niterói RJ, Brasil;

${ }^{2}$ Hospital Albert Einstein, Departamento de Neurologia, São Paulo SP, Brasil;

${ }^{3}$ Universidade Federal do Rio de Janeiro, Departamento de Epidemiologia, Rio de Janeiro RJ, Brasil.

Correspondence: Maria Eduarda Nobre; Rua Gildasio Amado, 55 / sala 714; 22631-020 Rio de Janeiro RJ, Brasil;E-mail nobreme@globo.com

Conflict of interest: There is no conflict of interest to declare.
}

Received 11 June 2016; Received in final form 23 April 2017; Accepted 27 June 2017. 
Hypothalamic activation during the attacks was proven by means of positron emission tomography and this was a milestone in the therapeutic approach ${ }^{4}$. In addition to positron emission tomography findings, studies using magnetic resonance spectroscopy demonstrated the presence of asymmetry in this area. It seems that the posterior inferior hypothalamus is larger in patients with cluster headaches, during and outside cluster periods. The areas found in studies with different examinations were identical ${ }^{5}$.

Therefore, findings in relation to cluster headaches drive forward new clinical and surgical treatment with stereotactic stimulation of the posterior inferior hypothalamus, particularly for patients with chronic cluster headaches with no response to clinical treatment. The stimulation that directly or indirectly affects the hypothalamus has proven efficacy in the prevention of cluster headaches ${ }^{6,7}$.

Clomiphene is a nonsteroidal agent with estrogenic and anti-estrogenic properties, which may induce ovulation in women who do not ovulate. It competes with endogenous estrogen at hypothalamic estrogen receptors, preventing the hypothalamus from recognizing sufficient levels and decreasing the secretion of gonadotropin-releasing hormone $(\mathrm{GnRH})$, with no negative feedback. Without being interrupted, the hypothalamus continues stimulating the pituitary gland by increasing GnRH secretion. The pituitary increases the levels of follicle-stimulating hormone (FSH) and luteinizing hormone (LH) and these act on the gonads, stimulating the ovaries and testicles to produce estrogens and androgens ${ }^{8,9,10}$.

In women, FSH and LH stimulate ovaries to produce progesterone and estrogens. Estrogens are responsible for female sexual development and for monthly hormonal alterations. Estrogens are, in reality, a group of hormones called estradiol, estriol and estrone, with the most active being estradiol E2. Their roles are practically identical ${ }^{11}$. Estrogens have extended action in the female body and are responsible for the estro (female side) of the cellular universe, female anatomy and female behavior, and have only a subtle manifestation in males. With maximized activity during the menacme, it acts on the ovary (maturing the follicle and ovum), uterus, vagina, cervix, fertilization and fetus maintenance. Progesterone is a hormone directly linked to reproduction and is released during the second phase of the cycle in order to prepare the woman's body for pregnancy. Pregnant or not, the woman's behavior changes and differs from the estrogenic phase, which occurred before. The main androgenic products produced by the ovaries are dehydroepiandrosterone, testosterone and androstenedione. Testosterone is considered the most potent of the androgens ${ }^{12}$.

In men, the FSH stimulates spermatogenesis by the cells of the seminiferous tubules by producing estrogens, while LH stimulates the production of testosterone by the interstitial cells of the testicles. Testicular secretion of testosterone is regulated primarily by the secretion of LH by the pituitary gland, which stimulates steroidogenesis in Leydig cells, increasing the substrate for its production and regulating testicular blood flow. The hypothalamic GnRH is secreted occasionally and controls the secretion of LH. Testosterone, in turn, provides negative feedback, inhibiting the secretion of $\mathrm{GnRH}^{12}$.

The main androgens produced in the adrenal gland are androstenedione and dehydroepiandrosterone. Despite having low activity, these are converted into testosterone (more active) in the peripheral tissues. The adrenal gland produces residual quantities of testosterone. In women, the adrenal gland is responsible for the production of between $50 \%$ and $60 \%$ of androgenic requirements, but in men, the biological significance of this secretion is minimal ${ }^{11,12}$.

The steroid hormones produced by the gonads have a fundamental role in the metabolism of lipids and proteins. From among the androgens, testosterone has an important effect on the circulating levels of cholesterol, increasing lowdensity lipoproteins and reducing high-density lipoproteins ${ }^{11}$.

It seems that the direct replacement of testosterone does not affect cluster headache attacks, possibly because synthetic testosterone does not reach hypothalamic receptors. Moreover, clomiphene is the only form of testosterone replacement that does not interfere in men's spermatogenesis or in women's fertility 9 . Clomiphene, which showed a partial effect in a case of short-lasting unilateral neuralgiform headache with conjunctival injection and tearing (SUNCT), and absolute effect in another two cases: one case of SUNCT and a described case of refractory chronic cluster headaches. The medication effect seemed to be similar to that which occurs in direct surgical stimulation. Therefore, clomiphene is a putative candidate for cluster headache prevention ${ }^{8,9,10}$.

Suffering from intractable cluster headaches is an atrocious condition that affects all aspects of the patients' lives and may even lead to suicide as a desperate solution to stop the pain. We must remember that patients with difficult-tomanage cluster headaches, including patients whose episodic cluster period is longer, frequently need more efficient treatment in order to control attacks8.

The absolute control of attacks as early as possible might shorten the cluster periods, or increase the remission period, or even prevent episodic pain from becoming chronic. As this process is still unknown, we should aim at decreasing the suffering of patients with difficult-to-manage cluster headaches, reduce the medication dosage or even change the pattern of attacks ${ }^{8,9}$.

\section{METHODS}

We report on the experience of a tertiary headache center with clomiphene treatment in 15 patients suffering from episodic and chronic headaches fulfilling the ICHD (International Classification of Headache Disorder) III edition - beta criteria. These patients' chronic and episodic headaches were refractory to current prophylactic medication. The episodic headache patients presented with longer cluster periods, exceeding the average time of previous cluster cycles. 
These patients accepted hormone therapy despite having been made aware of the limited number of studies published on the subject.

The following tests were performed: complete blood count, glucose, urea, creatinine, sodium, potassium, aspartate aminotransferase (AST), alanine aminotransferase (ALT), gamma glutamyltransferase (GGT), total cholesterol and fractions, triglycerides, dehydroepiandrosterone, total and free testosterone, sex hormone-binding globulin, free testosterone index, androstenedione, FSH, LH, progesterone, estradiol E2 and prostate-specific antigen in males. Female patients had a transvaginal ultrasound in addition to the biochemical tests. Patients with risk factors for ischemic disease were excluded from the study. Tests were repeated every month until the absolute control of attacks.

Previous medications were maintained so that withdrawal did not interfere in the interpretation of results. Clomiphene was prescribed in morning doses of $300 \mathrm{mg}$ for two days, $100 \mathrm{mg}$ for nine days, followed by $50 \mathrm{mg}$.

Demographic and clinical data were ascertained: sex, age, pattern of pain, disease history, smoking habits, total testosterone before the use of clomiphene, total testosterone after the use of clomiphene, number of days using clomiphene, number of previous bouts, number of consecutive months of pain in the current cluster in episodic and chronic cases, number of months since chronicity, number of days until the complete absence of pain but still in the cluster period and the number of days up until the complete remission characterizing the end of the cluster.

The latter two events were characterized as endpoints in clomiphene treatment. Survival analysis techniques were used considering the elapsed time between:

1) the start of the treatment with clomiphene and complete absence of pain, but still in the cluster period (defined by patients as any sensation besides pain that made them consider that they were still in the attack period);

2) the start of the treatment with clomiphene and complete remission characterizing the end of the cluster period;

3) total absence of pain and complete remission.

Incidence rates were calculated, and the distribution of time elapsed until each successful event, was described by means of respective quartiles. The accumulated probabilities until each successful event was estimated based on the Kaplan-Meier method ${ }^{13}$.

The research project was approved by the Ethics in Research Committee ( $n^{\circ}$ 2.149.356). All individuals were informed about the purpose of the research and signed the informed consent document.

\section{RESULTS}

Ten men and five women were studied. Seven patients were chronic and eight episodic headache. Ages varied between 25 and 64 years and the average age was 40.4 years.

Disease onset ranged from 2-27 years, with an average of 10.6 years. The number of bouts varied from three to 16 and the average was 6.6 bouts four patients presented with one bout, as they were considered chronic right from the beginning.

The average time of pain before clomiphene varied from one to 350 months and the average was 41.7 months.

Total testosterone was below the gender-related lower limit in three patients and at the lower limit in all others. After the use of clomiphene, there was an increase in testosterone to normal limits. Only three patients were above the normal upper limit.

Clomiphene was used for a minimum of 45 days and a maximum of 180 days. Average treatment time was 104 days. There were no significant side effects. One patient presented with mild acne and another presented with an ovarian cyst. Both conditions regressed when the medication was discontinued. There was no weight gain or significant biochemical changes of the blood.

The start of the treatment with clomiphene and the total absence of pain, but still in the cluster period (Table 1 and Figure 1).

The average time since the start of the treatment with clomiphene until the disappearance of pain was 15 days.

The reading with regards to the 1st (p25) and 3rd quartile (p75) is similar; $25 \%$ of patients reported the disappearance of pain within 10 days after the start of treatment and $75 \%$ within 30 days.

The start of treatment with clomiphene and the complete remission, characterizes the end of the cluster (Table 2 and Figure 2).

The average time from the start of the treatment with clomiphene until cluster remission was 60 days.

Table 1. Number of days up until the total absence of pain.

\begin{tabular}{lcccccc}
\hline \multirow{2}{*}{ Variable } & \multirow{2}{*}{$\begin{array}{c}\text { Time } \\
\text { at risk }\end{array}$} & Incidence & No. of & \multicolumn{3}{c}{ Survival time } \\
\cline { 5 - 7 } & rate & subjects & $25 \%$ & $50 \%$ & $75 \%$ \\
\hline Chronic & 285 & 0.0245614 & 7 & 25 & 30 & 60 \\
Episodic & 98 & 0.0816327 & 8 & 8 & 10 & 15 \\
Total & 383 & 0.0391645 & 15 & 10 & 15 & 30 \\
\hline
\end{tabular}

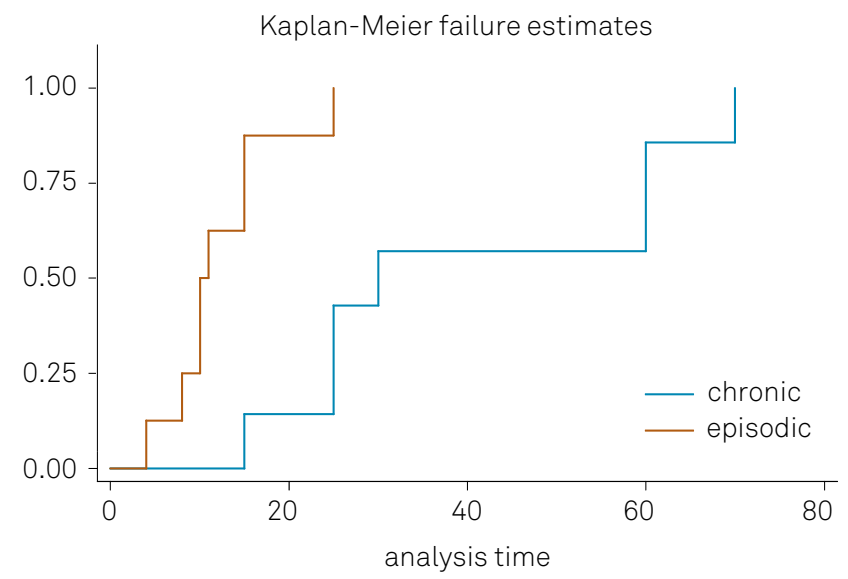

Figure 1. Graph showing the number of days up until the total absence of pain. 
Table 2. Number of days until complete remission .

\begin{tabular}{lcccccc}
\multirow{2}{*}{ Variable } & \multirow{2}{*}{$\begin{array}{c}\text { Time } \\
\text { at risk }\end{array}$} & $\begin{array}{c}\text { Incidence } \\
\text { rate }\end{array}$ & No. of & & \multicolumn{3}{c}{ Survival time } \\
\cline { 5 - 7 } & subjects & $25 \%$ & $50 \%$ & $75 \%$ \\
\hline Chronic & 486 & 0.0144033 & 7 & 60 & 60 & 90 \\
Episodic & 380 & 0.0210526 & 8 & 22 & 30 & 43 \\
Total & 866 & 0.017321 & 15 & 30 & 60 & 90 \\
\hline
\end{tabular}

Kaplan-Meier failure estimates

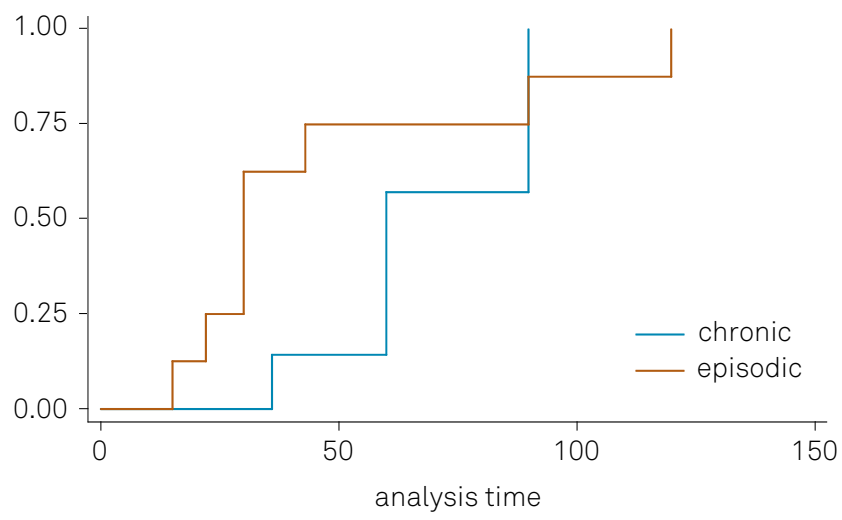

Figure 2. Graph showing the number of days until complete remission

In the evaluation of complete remission, $25 \%$ of patients reported complete remission within 30 days after the start of the treatment (60 days in chronic patients and 22 in episodic patients) and $75 \%$ within 90 days.

Total absence of pain and complete remission are in Table 3 and Figure 3.

After the disappearance of pain, the average time until cluster remission was 26 days.

In the evaluation between the length of pain-free time and complete remission, $25 \%$ of patients had an interval of 18 days and $75 \%$ of patients had an interval of 35 days.

The end of the actual cluster cycle occurred in all patients, including the chronic individuals.

Half the patients reported the disappearance of pain and the remission of clusters within 15 and 60 days, respectively. Once the pain had disappeared, half the patients reported the remission of clusters in up to 26 days.

\section{DISCUSSION}

The use of clomiphene in the treatment of cluster headache is recent. Two papers have reported its use. Rozen reported on a patient who had experienced chronic cluster headaches for 17 years before the treatment, and who had a remission of 3.5 years before the next cluster cycle. He then restarted taking clomiphene and once again had positive results ${ }^{14}$. Another two reports of SUNCT cases showed positive results ${ }^{8,9,10}$.
Table 3. Number of days between the end of pain and complete remission.

\begin{tabular}{lccccccc}
\hline \multirow{2}{*}{ Variable } & \multirow{2}{*}{$\begin{array}{c}\text { Time } \\
\text { at risk }\end{array}$} & $\begin{array}{c}\text { Incidence } \\
\text { rate }\end{array}$ & \multirow{2}{*}{$\begin{array}{c}\text { No. of } \\
\text { subjects }\end{array}$} & \multicolumn{3}{c}{ Survival time } \\
\cline { 5 - 8 } & & & $25 \%$ & $50 \%$ & $75 \%$ \\
\hline Chronic & 201 & 0.0348259 & 7 & 20 & 30 & 35 \\
Episodic & 282 & 0.0248227 & 7 & 15 & 20 & 82 \\
Total & 483 & 0.0289855 & 14 & 18 & 26 & 35 \\
\hline
\end{tabular}

Kaplan-Meier failure estimates

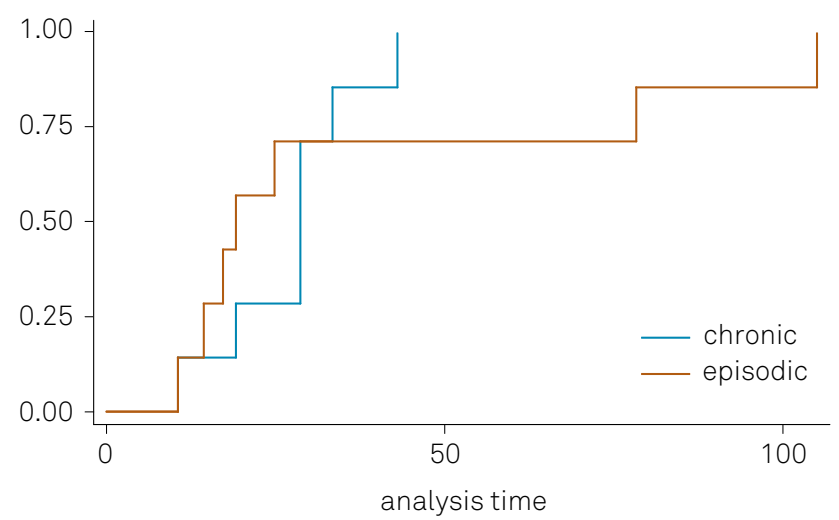

Figure 3. Graph showing the number of days between the end of pain and complete remission.

Clomiphene is a nonsteroidal agent with estrogenic and anti-estrogenic properties. This is because it binds to the hypothalamic estrogen receptors, preventing the hypothalamus from recognizing sufficient levels, and decreasing the secretion of GnRH, blocking a possible negative feedback ${ }^{8}$. Without being interrupted, the hypothalamus continues stimulating the pituitary gland by increasing GnRH secretion. The pituitary increases the levels of FSH and LH, which act on the gonads, stimulating the ovaries and the testicles to produce estrogens and androgens $\mathrm{s}^{8}$. The physiological and progressive increase of testosterone offers a putative explanation for the main effect in cluster headache treatment. Another hypothesis would be an action on orexinergic receptors, occurring at the same time as the blocking of estrogenic hypothalamic receptors, leading to an increase of orexin-A, which could suppress trigeminal autonomic activation. Orexin has been suggested as an important neuropeptide in the pathogenesis of cluster headaches ${ }^{8}$.

Clomiphene has proven to be a very safe drug but possible side effects should be closely observed, particularly if long term use is necessary. Referral to gynecologists, urologists and endocrinologists may help in the safety and risk/benefit evaluation ${ }^{15}$.

There is no consensus regarding the right dosage. It varies between 25 and $400 \mathrm{mg} /$ day; however, 50 to $100 \mathrm{mg}$ was used in most studies, giving the best results in testosterone levels. It should be taken once a day in order to cross the bloodbrain barrier and quickly reach hypothalamic receptors ${ }^{16}$.

As opposed to synthetic testosterone, clomiphene can be used by men who still wish to have children since it does not 
affect spermatogenesis. It is used in cases of male infertility to stimulate the germination epithelium by means of increasing FSH and LH secretion. It is the testosterone replacement therapy of choice for young men in order to preserve fertility. In the absence of any protocol, and as it is an innovative treatment, we established a protocol based on treatments that need a quick hypothalamic response. Cases related to the use of anabolic steroids that range from impotence to psychiatric emergencies are examples. There is a suppression of the hypothalamic-pituitary-gonadal axis and higher initial doses are used for a faster hypothalamic response. We opted to use $300 \mathrm{mg}$ during the first two days, $100 \mathrm{mg}$ for nine days and maintained a dosage of $50 \mathrm{mg}$ afterwards ${ }^{17,18,19}$.

In women, it stimulates ovulation. A barrier contraceptive method is necessary to avoid an unwanted pregnancy, which often is multiple ${ }^{12}$. We suggest a levonorgestrel-releasing intrauterine system.

We observed that the use of clomiphene turned chronic headaches into episodic, and episodic patients experienced cluster cycle interruption. These episodic patients had presented with extended cluster periods that were not responding to effective treatment during previous cluster cycles and some were becoming chronic. After gradually discontinuing clomiphene, all preventive medicines were suspended.

In general, there was absolute adherence by patients to the use of clomiphene. Even when they were aware of the hormonal changes that could occur, all were willing to comply because there was no other solution to ease the suffering. Surgical procedures were not performed, because they were not indicated or were denied by patients.

Further studies need to look at testosterone levels during the remission period; a slow and progressive decrease in testosterone levels during remission could eventually be a surrogate marker of an approach of the next bout. Maintenance of normal levels might be a preventive treatment for the next cluster period.

Our study suggests clomiphene could be used for chronic and episodic cluster headache patients, considerably improving their quality of life. Clomiphene could be tried before a surgical procedure is indicated. Randomized clinical trials should be performed to test the role of clomiphene in cluster headaches.

In conclusion, clomiphene treatment was effective and tolerable in refractory episodic and chronic cluster headaches. It interrupted chronicity in all patients, suggesting the drug's positive effect.

We suggest the inclusion of a testosterone evaluation in the initial approach of all cluster headache patients. If there are no contraindications, clomiphene should be indicated for episodic cases of extended cluster periods and for general chronic headaches, and not limited to refractory patients.

Additionally, patients should only be considered refractory after clomiphene treatment.

\section{References}

1. Ambrosini A, Schoenen J. Commentary on Fontaine et al.: Safety and efficacy of deep brain stimulation in refractory cluster headache: a randomized placebo-controlled double-blind trial followed by a 1-year open extension. J Headache Pain. 2010;11(1):21-2. https://doi.org/10.1007/s10194-009-0184-5

2. May A, Leone M. Update on cluster headache. Curr Opin Neurol. 2003;16(3):333-40. https://doi.org/10.1097/00019052-200306000-00013

3. Romiti A, Martelleti P, Gallo MF, Giacovazzo M. Low plasma testosterone levels in cluster headache. Cephalalgia. 1983;3(1):41-4. https://doi.org/10.1046/j.1468-2982.1983.0301041.x

4. May A, Bahra A, Büchel C, Frackowiak RS, Goadsby PJ. Hypothalamic activation in cluster headache attacks. Lancet. 1998;352(9124):275-8. https://doi.org/10.1016/S0140-6736(98)02470-2

5. Aurora SK. Etiology and pathogenesis of cluster headache. Curr Pain Headache. 2002;6:71-5. https://doi.org/10.1007/s11916-002-0027-4

6. Leone M, Franzini A, Broggi G, Bussone G. Hypothalamic deep brain stimulation for intractable chronic cluster headache: a 3-year follow-up. Neurol Sci. 2003;24:143-5.

7. Bartsch T, Pinsker MO, Rasche D, Kinfe T, Hertel F, Diener HC Hypothalamic deep brain stimulation for cluster headache: experience from a new multicase series. Cephalalgia. 2008;28(3):285-95. https://doi.org/10.1111/j.1468-2982.2007.01531.x PMID:18254897

8. Rozen T. Clomiphene citrate for treatment refractory chronic cluster headache. Headache. 2008;48(2):286-90. https://doi.org/10.1111/j.1526-4610.2007.00995.x

9. Rozen TD, Saper JR, Sheftell FD, Dodick DW. Clomiphene citrate as a new treatment for SUNCT: hormonal manipulation for hypothalamic-influenced trigeminal autonomic cephalalgias. Headache. 2005;45(6):754-6. https://doi.org/10.1111/j.1526-4610.2005.05143_2.x
10. Rozen TD. Complete alleviation of treatment refractory primary SUNCT syndrome with clomiphene citrate (a medicinal deep brain hypothalamic modulator). Cephalalgia. 2014;34(12):1021-4. https://doi.org/10.1177/0333102414527647

11. Gebara OCE, Vieira NW, Meyer JW, Calich ALG, Tai EJ, Pierri H et al. Efeitos cardiovasculares da testosterona. Arq Bras Cardiol. 2002;79(6):644-9. https://doi.org/10.1590/S0066-782X2002001500013

12. Strauss JE III, Barbieri RL. Yen \& Jaffe's Reproductive endocrinology: physiology, pathophysiology and clinical management. 6th ed. Philadelphia: Saunders Elsevier; 2009.

13. Gordis L. Epidemiology. 4th ed. Philadelphia: Saunders Elsevier; 2009.

14. Rozen T. Clomiphene citrate as a preventive treatment for intractable chronic cluster headache: a second reported case with long-term follow-up. Headache. 2008;48(2):286-90. https://doi.org/10.1111/head.12491

15. Dickey RP, Holtkamp DE. Development, pharmacology and clinical experience with clomiphene citrate. Hum Reprod Update 1996;2(6):483-506. https://doi.org/10.1111/j.1464-410X.2011.10702.x

16. Katz DJ, Nabulsi O, Tal R, Mulhall JP. Outcomes of clomiphene citrate treatment in young hypogonadal men. BJU Int. 2012;110(4):573-8.

17. Kanayama G, Brower KJ, Wood RI, Hudson JI, Pope HG Jr. Treatment of anabolic-androgenic steroid dependence: Emerging evidence and its implications. Drug Alcohol Depend. 2010;109(1-3):6-13. https://doi.org/10.1016/j.drugalcdep.2010.01.011

18. Ross LS, Kandel GL, Prinz LM, Auletta F. Clomiphene treatment of the idiopathic hypofertile male: high-dose, alternate-day therapy. Fertil Steril. 1980;33(6):618-23. https://doi.org/10.1016/S0015-0282(16)44775-8

19. Bickelman C, Ferries L, Eaton RP. Impotence related to anabolic steroid use in a body builder. Response to clomiphene citrate. West J Med. 1995;162(2):158-60. 